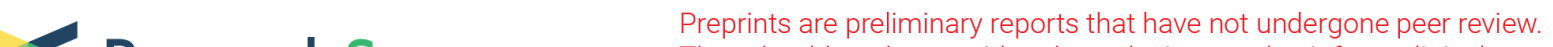 Research Square They should not be considered conclusive, used to inform clinical practice, or referenced by the media as validated information.
}

\section{Transit Time Flow Measurement Predicts Graft Patency in Off-pump Coronary Artery Bypass Grafting Upon 5-Year Angiographic Follow-up}

\section{caiwu zeng}

Beijing Anzhen Hospital

\section{Xiaomi Li}

Beijing An Zhen Hospital: Capital Medical University Affiliated Anzhen Hospital

\section{Yan Dai}

Beijing An Zhen Hospital: Capital Medical University Affiliated Anzhen Hospital

\section{Ye Zhou}

Beijing An Zhen Hospital: Capital Medical University Affiliated Anzhen Hospital

\section{Chenglong Li}

Beijing An Zhen Hospital: Capital Medical University Affiliated Anzhen Hospital

\section{Nan Liu}

Beijing An Zhen Hospital: Capital Medical University Affiliated Anzhen Hospital

Jiangang Wang ( $\sim$ jiangangwang@ccmu.edu.cn )

Capital Medical University Affiliated Anzhen Hospital https://orcid.org/0000-0002-3656-2916

\section{Research article}

Keywords: Off-pump coronary artery bypass grafting, Transit time flow measurement, Coronary angiography, Graft dysfunction

Posted Date: December 15th, 2020

DOI: https://doi.org/10.21203/rs.3.rs-127853/v1

License: (c) (i) This work is licensed under a Creative Commons Attribution 4.0 International License. Read Full License

Version of Record: A version of this preprint was published at Journal of Cardiothoracic Surgery on November 21st, 2021. See the published version at https://doi.org/10.1186/s13019-021-01716-3. 


\section{Abstract}

Objective: This retrospective study sought to evaluate the efficacy of transit time flow measurement (TTFM) as a means of predicting bypass graft patency as assessed by coronary artery angiography (CAG) upon 5-year follow-up.

Method: Of 311 patients undergone isolated off-pump coronary artery bypass graft (CABG) surgery from January 2014 through December 2014, 202 (65\%) underwent both intraoperative TTFM and angiography at follow-up. 610 grafts, 202 left internal mammary artery grafts and 408 saphenous vein grafts were checked. Any grafts that exhibited Fitzgibbon type $\mathrm{B}$ or $\mathrm{O}$ lesions upon angiographic evaluation were considered to be failing. Receiver operating characteristic (ROC) curves were used to identify the optimal TTFM values for predicting graft patency.

Results: A total of 610 grafts were included in this analysis, including 202 LIMA grafts and 408 SV grafts, of which 107, 129, 129, and 43 anastomosed to DIAG, OM, PDA, and PLA, respectively. LIMA, DIAG, OM, PDA, and PLA bypass grafts had overall patency rates of $95.0 \%, 74.8 \%, 73.6 \%, 71.5 \%$, and $74.4 \%$, respectively, upon 5-year follow up. No significant differences in TTFM values (MGF, PI, and DF) were observed when comparing outcomes associated with individual or sequential SV grafting. MGF was found to be predictive of graft failure regardless of the target vessel $(P<0.05)$. While PI was found to predict LIMA, OM, and PDA graft failure $(P<0.05)$, it was not associated with the failure of grafts associated with DIAG and PLA vessels. Similarly, DF was found to predict OM and PDA graft failure $(P<0.05)$, but was not significantly associated with the failure of grafts associated with LIMA, DIAG, or PLA vessels.

Conclusion: LIMA bypass grafts were associated with better 5-year graft patency relative to SV bypass grafts. Similar graft patency rates were observed for both individual and sequential bypass grafts. TTFM was able to predict bypass graft failure in patients that underwent off-pump CABG surgery, with MGF cutoff values for LIMA, DIAG, OM, PDA, and PLA grafts being $14.5 \mathrm{~mL} / \mathrm{min}, 14.5 \mathrm{~mL} / \mathrm{min}, 14.5 \mathrm{~mL} / \mathrm{min}, 13.5$ $\mathrm{mL} / \mathrm{min}$, and $16.5 \mathrm{~mL} / \mathrm{min}$, respectively.

\section{Background}

Coronary artery bypass graft (CABG) surgery outcomes have significantly improved over the last 50 years [1], with this treatment remaining the optimal treatment for those with complex multivessel disease [2]. Intraoperative graft patency is a primary determinant of the short- and long-term success of CAGB surgery [3]. While coronary artery angiography (CAG) is the gold-standard approach used to assess graft patency, it can be an inconvenient and invasive procedure when conducted intraoperatively. As such, intraoperative graft function is most often assessed based upon transit time flow measurement (TTFM) values, which have the potential to significantly improve CABG procedure quality and patient clinical outcomes [6]. 
TTFM is typically used to evaluate intraoperative graft patency in accordance with guidelines published in 2010 [4], which additional support from the 2018 ESC/EACTS Guidelines on myocardial revascularization that provided a class-lla recommendation for the use of TTFM for intraoperative graft assessment [5].

Few published studies to date, however, have evaluated the reliability of TTFM as a means of predicting long-term CAG graft patency findings in patients undergoing off-pump CABG surgery. This study was therefore designed to assess the ability of TTFM parameters to predict 5-year postoperative graft patency outcomes in off-pump CABG patients.

\section{Materials And Method}

\section{Patients and study design}

Between January 2014 and December 2014, 311 total patients underwent isolated off-pump CABG surgery at Beijing Anzhen Hospital, Capital Medical University. Patients included in the present study were those with stable angina, a left ventricle ejection fraction (LVEF) $\geq 50 \%$, and a left ventricular enddiastolic diameter (LVEDD) of $\leq 60 \mathrm{~mm}$.

\section{Operative procedures}

Median sternotomy, standard cannulation, and off-pump procedure stabilizers were employed for the treatment of all patients. Left internal mammary artery (LIMA) grafts were harvested as pedicles, while saphenous vein (SV) grafts were harvested via an open technique. End-to-side anastomoses were conducted in a continuous manner using 6-0 sutures for proximal aortic connections during partial aortic clamping and using 7-0 sutures for the terminal bypass. Side-to-side anti-parallel anastomoses were conducted in a continuous manner using 7-0 sutures for the sequential bypasses.

\section{Intraoperative graft flow measurement}

A TTFM (VQ1001; Medi-stim AS, Oslo, Norway) approach was used to measure intraoperative graft flow parameters, including MGF, PI, and the DF. MGF was measured in $\mathrm{mL} /$ minute, while $\mathrm{PI}$ was measured as the difference in peak systolic flow minus peak diastolic flow divided by the median flow and was used to estimate graft resistance. DF was measured as the percentage of the total flow during diastole. These TTFM procedures were recorded intraoperatively immediately prior to sternal closure with the transit-time flowmeter instrument and an appropriately sized probe that was able to fit tightly within the graft without causing compression. Measurements were made when the patient exhibited stable hemodynamics and a mean blood pressure of $70-90 \mathrm{mmHg}$.

\section{Postoperative follow-up}

After surgery, patients were treated with aspirin $(100 \mathrm{mg} / \mathrm{d}$ orally), atorvastatin calcium tablets $(10 \mathrm{mg} / \mathrm{d}$ orally), and clopidogrel $(75 \mathrm{mg} / \mathrm{d}$, orally). Other medications were prescribed as necessary. Postoperative 
follow-up was obtained via phone call or direct contact with patients or their families, and all patients underwent annual routine clinical assessment. At the 5-year follow-up time point, 28 patients had been lost to follow-up and 81 refused to undergo CAG. The remaining 202 patients $(65 \%)$ consented to undergo $C A G$, and therefore were enrolled in our final study.

\section{Postoperative angiography}

Two or more cardiologists independently analyzed angiographic recordings from each patient that had been collected using standard views, with grafts being assessed as per the Fitzgibbon classification system [7]. Each coronary anastomosis was considered to correspond to the distal end of a single bypass graft, regardless of trunk configuration. Excellent and unimpaired grafts were those with a grade $A$ designation, whereas type $B$ or type $O$ grafts were considered to be occluded.

\section{Statistical analysis}

Continuous data were given as means \pm standard deviation and were compared via unpaired Student's ttests. Categorical variables were given as frequencies and percentages, and were compared via chisquared tests or Fisher' exact test. Optimal MGF, PI, and DF cut-off values for the prediction of 5-year graft failure were determined using receiver operating characteristic (ROC) curves as the point nearest point to the best point (specificity $=1$, sensitivity $=1$; upper left corner) of these ROC curves. $P \bowtie 0.05$ was the significance threshold in this study, and SPSS v25 was used for all statistical testing.

\section{Results}

\section{Off-pump CABG patient characteristics}

Patient baseline characteristics are compiled in Table 1. 
Table 1

preoperative characteristic

\section{characteristic}

Demographics

Age

Male(\%)

$\operatorname{BMI}\left(\mathrm{Kg} / \mathrm{m}^{\wedge} 2\right)$

Cardiovascular risk factors

Hypertension

Diabetes mellitus

Hyperlipidemia

Current smoker

Comorbidities

Previous neurological events

Renal disease

COPD

Coronary lesion

Single vessel disease

Two-vessel disease

Three-vessel disease

Angina class

CCS I-II

$\operatorname{LVEDD}(\mathrm{mm})$

LVEF, \%

Euro SCORE
$58.6 \pm 7.3(38,76)$

$159(78.7 \%)$

$25.8 \pm 3.1(15.4,35.5)$

119 (58.9\%)

$66(32.7 \%)$

$55(27.2 \%)$

118 (58.4\%)

12 (5.9\%)

$5(2.5 \%)$

$15(7.4 \%)$

7(3.5\%)

43(21.3\%)

152(75.2\%)

$190(94.1 \%)$

$48.3 \pm 4.8(34,60)$

$61.8 \pm 5.9(50,77)$

$1.8 \pm 0.8(0,4)$

Abbreviations: BMI, body mass index; COPD, chronic obstructive pulmonary disease; CCS, Canadian Cardiovascular Society; LVEDD, left ventricular end diastolic diameter; LVEF, left ventricular ejection fraction.

\section{Graft Distributions}


In total, 610 total grafts (3.01 grafts/patient) were included in the present study, including 202 LIMA grafts anastomosed to the LAD, and 408 SV grafts that were anastomosed to DIAG, OM, PDA, and PLA in $107,129,129$, and 43 cases, respectively. A total of 66 patients were bypassed with a single distal SV graft, while 342 distal targets were sequentially bypassed with $141 \mathrm{SV}$ grafts, for a combined total of 408 distal anastomoses with 207 SV graft conduits. Among patients that underwent sequential bypass, 85 , 52 , and 4 underwent double, triple, and quadruple sequential SV bypass grafting, respectively.

\section{Ttfm Parameters}

No significant differences in TTFM parameters (MGF, PI, and DF) were observed when comparing individual and sequential SV grafting (Table 2), enabling us to analyze SV grafts in different distributions without taking grafting technique into consideration during these analyses.

Table 2

TTFM values of different bypass grafting technique in SVG

\begin{tabular}{|lllll|}
\hline Variable & Grafting technique & MGF & PI & DF \\
\hline DIAG & Individual grafting & $23.9 \pm 15.4(8,70)$ & $1.8 \pm 0.7(1,3)$ & $71.5 \pm 8.4(55,87)$ \\
\hline & Sequential grafting & $31.8 \pm 21.0(5,89)$ & $2.5 \pm 0.9(1.6)$ & $71.6 \pm 10.1(41,97)$ \\
\hline OM & Individual grafting & $28.8 \pm 20.5(6,71)$ & $2.8 \pm 1.9(1,9)$ & $66.1 \pm 11.7(47,87)$ \\
\hline PDA & Sequential grafting & $31.5 \pm 21.4(4,125)$ & $2.5 \pm 1.2(1,11)$ & $69.6 \pm 9.9(48,92)$ \\
\hline PLA & Individual grafting & $26.5 \pm 17.7(9,74)$ & $2.7 \pm 1.3(1,7)$ & $62.1 \pm 12.2(27,76)$ \\
\hline \multicolumn{7}{|l}{ Abbreviations: DIAG, diagonal artery; OM, obtuse marginal branch of circumflex artery; PDA, posterior } \\
descending artery; PLA, left posterior artery; MGF, mean graft flow; PI, pulsatile index; DF, diastolic \\
filtration.
\end{tabular}

TTFM values associated with different graft types are shown in Table 3. MGF and PI values were significantly higher in patent grafts relative to occluded grafts regardless of the target vessel $(P<0.05)$. While DF were significantly better in all patent OM and PDA grafts relative to occluded OM and PDA grafts $(P<0.05)$, no significant differences in these values were noted when comparing patent and occluded grafts associated with LIMA, DIAG, and PLA vessels. 
Table 3

TTFM values of bypass graft
MGF, $\mathrm{ml} / \mathrm{min}$
PI
$\mathrm{DF}, \%$

LIMA

\begin{tabular}{llll} 
Patent $(\mathrm{n}=192)$ & $35.6 \pm 21.4(6,130)$ & $2.2 \pm 0.8(0.9,5.0)$ & $71.0 \pm 8.5(35,99)$ \\
\hline Occlusion $(\mathrm{n}=10)$ & $14.3 \pm 5.8(10,27)$ & $3.2 \pm 1.4(1.5,5.8)$ & $68.5 \pm 9.1(56,80)$ \\
\hline P value & $\mathbb{0} .001$ & 0.049 & 0.357
\end{tabular}

DIAG

\begin{tabular}{llll} 
Patent $(\mathrm{n}=80)$ & $36.6 \pm 20.0(14,89)$ & $2.3 \pm 0.9(0.9,5.7)$ & $71.8 \pm 8.3(51,97)$ \\
\hline Occlusion $(\mathrm{n}=27)$ & $12.8 \pm 6.5(5,30)$ & $2.7 \pm 1.0(1.2,4.4)$ & $70.8 \pm 13.1(41,96)$ \\
\hline P value & $₫ 0.001$ & 0.044 & 0.702
\end{tabular}

$\mathrm{OM}$

\begin{tabular}{llll} 
Patent $(\mathrm{n}=95)$ & $37.4 \pm 21.1(15,125)$ & $2.3 \pm 1.0(0.5,8.6)$ & $71.4 \pm 9.3(49,92)$ \\
\hline Occlusion $(\mathrm{n}=34)$ & $13.6 \pm 6.3(4,34)$ & $3.4 \pm 1.7(0.9,10.6)$ & $62.1 \pm 9.9(47,83)$ \\
\hline P value & $\mathbb{0} 0.001$ & 0.001 & $\varangle 0.001$
\end{tabular}

PDA

\begin{tabular}{|c|c|c|c|}
\hline Patent(n = 91) & $32.3 \pm 19.9(10,86)$ & $2.3 \pm 1.3(0.8,9.6)$ & $66.5 \pm 9.8(27,85)$ \\
\hline Occlusion $(n=38)$ & $7.9 \pm 2.8(3,13)$ & $3.9 \pm 2.1(1.3,10.0)$ & $57.5 \pm 9.0(40,73)$ \\
\hline$P$ value & $\nabla 0.001$ & $\llbracket 0.001$ & 0.005 \\
\hline
\end{tabular}

PLA

\begin{tabular}{llll}
\hline Patent $(\mathrm{n}=32)$ & $32.5 \pm 14.2(16,73)$ & $2.0 \pm 1.0(0.3,4.8)$ & $67.0 \pm 9.9(44,83)$ \\
\hline Occlusion $(\mathrm{n}=11)$ & $14.2 \pm 5.6(7,25)$ & $2.9 \pm 1.4(1.3,6.3)$ & $67.4 \pm 16.5(42,98)$ \\
\hline P value & $\mathbb{0} .001$ & 0.021 & 0.925
\end{tabular}

Abbreviations: LIMA, left internal mammary artery; SVG, saphenous vein graft; $L A D$, left anterior descending artery; DIAG, diagonal artery; OM, obtuse marginal branch of circumflex artery; PDA, posterior descending artery; PLA, left posterior artery; MGF, mean graft flow; PI, pulsatile index; DF, diastolic filtration.

\section{Angiographic Outcomes}

Postoperative 5-year graft patency rates for bypassed grafts in LAD, DIAG, OM, PDA, and PLA vessels were $95.0 \%, 74.8 \%, 73.6 \%, 71.5 \%$, and $74.4 \%$, respectively (Fig. 1). SV grafts were divided into subgroups 
based upon the employed bypass grafting approach (Fig. 2). No significant differences in SV graft patency were observed for DIAG, OM, PDA, or PLA grafts ( $p=0.064,0.137,0.751,1$, respectively) when comparing individual and sequential grafting.

\section{Roc Curve Analyses}

ROC curves corresponding to different graft types are shown in Fig. 3 and Table 4. ROC curve analyses of intraoperative TTFM values revealed that MGF (AUC: 0.875; $P<0.001$ ) and PI (AUC: $0.725 ; P=0.017$ ) values were able to predict LIMA graft failure. The optimal MGF cut-off value for predicting 5-year graft failure was found to be $14.5 \mathrm{~mL} / \mathrm{min}$, with a sensitivity of $89.6 \%$ and a specificity of $80.0 \%$. The optimal PI cut-off value for predicting 5-year graft failure was found to be $3.45 \mathrm{~mL} / \mathrm{min}$, with a sensitivity of $91.7 \%$ and a specificity of $60.0 \%$.In contrast, DF (AUC: $0.560 ; P=0.525)$ offered negligible predictive value for LIMA graft patency rates. 
Table 4

ROC analysis of the TTFM
Variables
Cut-off AUC $\quad 95 \% \mathrm{Cl}$
P-value Sensitivity
Specificity

LIMA

$\begin{array}{lllllll}\text { MGF } & 14.5 & 0.875 & 0.789 \sim 0.961 & \otimes 0.001 & 0.896 & 0.800 \\ \text { PI } & 3.45 & 0.725 & 0.536-0.914 & 0.017 & 0.917 & 0.600 \\ \text { DF } & 57.5 & 0.560 & 0.357-0.762 & 0.525 & 0.984 & 0.300\end{array}$

DIAG

$\begin{array}{lllllll}\text { MGF } & 14.5 & 0.921 & 0.857-0.985 & \Downarrow 0.001 & 0.968 & 0.750 \\ \text { PI } & 2.45 & 0.633 & 0.495-0.772 & 0.056 & 0.698 & 0.625 \\ \text { DF } & 60.5 & 0.484 & 0.325-0.642 & 0.816 & 0.937 & 0.292\end{array}$

OM

$\begin{array}{lllllll}\text { MGF } & 14.5 & 0.935 & 0.876-0.993 & \bigotimes 0.001 & 1 & 0.769 \\ \text { PI } & 2.85 & 0.751 & 0.628-0.873 & \varangle 0.001 & 0.795 & 0.692 \\ \text { DF } & 60.5 & 0.737 & 0.621-0.853 & \bigotimes 0.001 & 0.877 & 0.500\end{array}$

PDA

$\begin{array}{lllllll}\text { MGF } & 13.5 & 0.956 & 0.911-1 & \varangle 0.001 & 0.926 & 0.931 \\ \text { PI } & 2.65 & 0.755 & 0.651-0.858 & \varangle 0.001 & 0.735 & 0.690 \\ \text { DF } & 67.5 & 0.689 & 0.576-0.802 & 0.003 & 0.456 & 0.828\end{array}$

PLA

\begin{tabular}{lllllll} 
MGF & 16.5 & 0.905 & $0.794-1$ & $\varangle 0.001$ & 0.952 & 0.700 \\
\hline PI & 1.85 & 0.690 & $0.495-0.886$ & 0.091 & 0.524 & 0.900 \\
\hline DF & 60.5 & 0.545 & $0.287-0.803$ & 0.688 & 0.810 & 0.500
\end{tabular}

The ROC analysis representing the cut-off graft flow for predicting 5-year Follow-up graft failure. Abbreviations: ROC, receiver operating characteristic; LIMA, left internal mammary artery; SVG, saphenous vein graft; MGF, mean graft flow; PI, pulsatile index; DF, diastolic filtration; AUC, area under curve; $\mathrm{Cl}$, confidence interval.

For SV grafts, MGF values were found to be predictive of graft failure regardless of the target vessel $(\mathrm{P}<$ 0.05). Optimal MGF cut-off values for DIAG, OM, PDA, and PLA grafts were $14.5 \mathrm{~mL} / \mathrm{min}, 14.5 \mathrm{~mL} / \mathrm{min}$, $13.5 \mathrm{~mL} / \mathrm{min}$, and $16.5 \mathrm{~mL} / \mathrm{min}$, respectively, with respective sensitivity values of $96.8 \%, 100 \%, 92.6 \%$, and $95.2 \%$, and with respective specificity values of $75.0 \%, 76.9 \%, 93.1 \%$, and $70.0 \%$. While PI was found to offer value as a means of predicting $\mathrm{OM}$ and PDA graft failure $(\mathrm{P}<0.001)$, it offered no such predictive 
value for DIAG and PLA grafts. Similarly, while DF values were able to predict OM and PDA graft failure $(P<0.05)$, they were unable to predict the failure of DIAG or PLA grafts.

\section{Discussion}

Herein, we found that LIMA bypass grafts were associated with superior rates of 5-year patency as compared with SV bypass grafts, with similar 5-year patency rates for sequential and individual SV grafts. Our primary finding is that intraoperative MGF can strongly predict 5-year LIMA and SV graft patency, whereas the PI and DF TTFM parameters cannot reliably predict these outcomes. Importantly, we additionally measured optimal MGF cut-off values for the prediction of LIMA, DIAG, OM, PDA, and PLA graft failure $(14.5 \mathrm{~mL} / \mathrm{min}, 14.5 \mathrm{~mL} / \mathrm{min}, 14.5 \mathrm{~mL} / \mathrm{min}, 13.5 \mathrm{~mL} / \mathrm{min}$, and $16.5 \mathrm{~mL} / \mathrm{min}$, respectively).

Previously published guidelines recommend intraoperative graft assessment $[4,5]$. Specifically, MGF is recommended to remain $>20 \mathrm{~mL} / \mathrm{min}$, with a PI value of $<5$. However, these guidelines fail to take graft type of anastomosis methodology into account, and they do not provide concrete cut-off values that can be used to predict graft failure. These recommendations were based on a retrospective analysis of 3-year follow-up data for 990 arterial grafts in patients that underwent on-pump CABG surgery [8]. As this study did not analyze SV grafts, these guidelines may not be well-suited to such grafts, and in the absence of any angiographic follow-up it is difficult to evaluate the relationship between intraoperative TTFM parameters and long-term graft patency. Furthermore, controversy remains regarding rates of graft patency associated with off-pump and on-pump CABG surgery. Hattler et al. [9] found on-pump CABG to be associated with excellent graft patency rates, whereas Puskas et al. [10] detected comparable patency rates when comparing on-pump and off-pump CABG outcomes. Herein, we assessed both LIMA and SV grafts in patients that underwent CABG surgery for whom angiographic follow-up data were available in an effort to supplement and improve upon these prior guidelines.

Relatively few studies to date have compared TTFM measurements with angiographic follow-up data, and results from such analyses have been inconsistent. Singh et al. [11] for example, studied 156 patients that underwent CABG surgery and that were randomized to intraoperative graft assessment or no assessment groups, detecting no significant differences in graft patency rates as a function of whether or not intraoperative graft assessment was conducted. In contrast, Quin et al. [12] assessed outcomes for 2203 patients that underwent CABG surgery and found that FitzGibbon grade A patency was less frequently detected for grafts with low intraoperative MGF values relative to grafts with normal intraoperative flow. They also found FitzGibbon grade A patency to be negatively correlated with PI values. We also found MGF values to strongly predict the long-term patency of LIMA and SV grafts, whereas PI was only a reliable predictor of LIMA graft patency. Relatively few studies have examined relationships between graft patency rates and TTFM parameters in patients undergoing off-pump CABG surgery. One reason for this is the fact that many factors can influence the readouts from this analysis, including graft quality and type, the nature of the coronary artery, hemoglobin levels, and individual patient hemodynamics $[13,14]$. 
All LIMA grafts in patients in the present study were anastomosed to the LAD, with an overall 5-year patency rate of $95.0 \%$, while DIAG, OM, PDA, and PLA SV grafts exhibited 5-year patency rates of $74.8 \%$, $73.6 \%, 71.5 \%$, and $74.4 \%$, respectively. LIMA grafts were associated with better 5 -year patency rates relative to SV grafts in the present study. As long-term graft patency is maximized by the use of arterial grafts, and specifically the LIMA [15], all patients should receive a minimum of one arteria graft to the LAD barring exceptional circumstances [16]. SV graft patency rates for non-LAD targets, in contrast, are generally found to be suboptimal [17].

We observed similar patency rates when comparing individual and sequential SV bypass grafts. At present, there is no consensus regarding which of these grafting techniques is optimal. For example, Kim et al. conducted a study of 309 patients that underwent either sequential or individual SV CABG surgery, and concluded that sequential bypass grafting was associated with higher mean flow rates and with better mid-term patency relative to individual grafting [18]. This is in contrast to our findings and may be explained by the relatively short 14.8 month mean follow-up duration in this prior study. Over time, proximal anastomosis may be associated with higher rates of occlusion, potentially resulting in simultaneous myocardial ischemic events in multiple regions.

Herein we calculated optimal TTFM cut-off values for assessing graft failure risk in patients undergoing off-pump CABG surgery. For LIMA grafts, an MGF cut-off value of $14.5 \mathrm{~mL} / \mathrm{min}$ was found to be able to strongly predict graft patency $(A U C=0.875)$. at the same time, a PI cut-off value of 3.45 offered a moderate ability for LIMA grafts (AUC $=0.725)$. For DIAG, OM, PDA, and PLA grafts, we calculated optimal MGF cut-off values of $14.5 \mathrm{~mL} / \mathrm{min}(A U C=0.921), 14.5 \mathrm{~mL} / \mathrm{min}(A U C=0.935), 13.5 \mathrm{~mL} / \mathrm{min}(A U C=$ 0.956 ), and $16.5 \mathrm{~mL} / \mathrm{min}$ (AUC $=0.905)$, respectively. PI cut-off values for SV grafts were inconsistent. This suggests that MGF values can be reliably used to predict the failure of LIMA and SV grafts over a 5year period, whereas PI values are only of value when predicting LIMA graft failure over this same period. As $\mathrm{PI}$ is defined as (peak flow-base flow)/(MGF), it is thus related to graft type, vessel size, and bypass grafting technique, influencing its discriminative ability for SV grafts.

\section{Limitations}

There are certain limitations to this study. For one, it was retrospective in nature rather than a randomized controlled trial. In addition, the sample size in the present study was small, and all off-pump CABG surgeries described herein were conducted at a single center. In addition, the measurements taken during surgery may not truly reflect the capacity of a given graft to carry flow, as these measurements can be influenced by many factors including cardiac recovery and graft spasm.

\section{Conclusion}

TTFM values are able to predict rates of 5-year LIMA and SV graft failure in patients undergoing offpump CABG surgery. MGF cut-off values of $14.5 \mathrm{~mL} / \mathrm{min}, 14.5 \mathrm{~mL} / \mathrm{min}, 14.5 \mathrm{~mL} / \mathrm{min}, 13.5 \mathrm{~mL} / \mathrm{min}$, and $16.5 \mathrm{~mL} / \mathrm{min}$ were identified as optimal cut-off thresholds when predicting the failure of LIMA, DIAG, OM, 
PDA, and PLA grafts. It is therefore vital that MGF values be carefully monitored during off-pump CABG operations in order to ensure graft patency.

\section{Abbreviations}

CABG: coronary artery bypass grafting ; TTFM: Transit time flow measurement; MGF: mean graft flow; PI: pulsatile index; DF: diastolic filtration; LIMA: left internal mammary artery; SVG: Saphenous vein graft; LAD: left anterior descending artery; DIAG: Diagonal artery; OM: obtuse marginal branch of circumflex artery; PDA: posterior descending artery.

\section{Declarations}

\section{Acknowledgements}

Not applicable.

\section{Authors' contributions}

Caiwu Zeng: Investigation; Resources; Writing-original draft; Writing-review \& editing. Xiaomi Li: Format analysis. Yan Dai: Data curation. Zhou Ye: Methodology. Chenglong Li: Software. Nan Liu and Jian-Gang Wang: Conceptualization; Writing-original draft; Writing-review \& editing.

\section{Funding}

None.

\section{Availability of data and materials}

The data used to support the findings of this study are available from the corresponding author upon request.

\section{Ethics approval and consent participate}

The institutional review board at Anzhen hospital approved the usage of clinical data, and waived individual informed consent for this study.

\section{Consent for publication}

Not applicable.

\section{Competing interests}

The authors declare that they have no competing interests.

\section{References}


1. Head SJ, Kieser TM, Falk V, Huysmans HA, Kappetein AP. Coronary bypass grafting: part 1-the evolution over the first 50 years. Eur Heart J. 2013;34:2862-72.

2. Head SJ, Milojevic M, Daemen J, Ahn JM, Boersma E, Christiansen EH. Mortality after coronary artery bypass grafting versus percutaneous coronary intervention with stenting for coronary artery disease: a pooled analysis of individual patient data. Lancet. 2018;391:939-48.

3. Alexander JH, Hafley G, Harrington RA, et al. Efficacy, safety of edifoligide, an E2F transcription factor decoy, for prevention of vein graft failure following coronary artery bypass graft surgery: PREVENT IV: A randomized control trial. JAMA. 2005;294(19):2446-54.

4. Kolh P, Wijns W, Danchin N, et al. Guidelines on myocardial revascularization. Eur Heart J. 2010;31:2501-55.

5. Sousa-Uva M, Neumann F-J, Ahlsson A, Alfonso F, Banning AP, Benedetto U, et al. 2018 ESC/EACTS Guidelines on myocardial revascularization. Eur J Cardiothorac Surg. 2019;55:4-90.

6. Daniel JFM, Thuijs, Margreet WA, Bekker DP, Taggart A, Pieter Kappetein TM, Kieser D, Wendt, et al. Improving coronary artery bypass grafting: a systematic review and meta-analysis on the impact of adopting transit-time flow measurement. Eur J Cardiothorac Surg. 2019;56(4):654-63.

7. FitzGibbon GM, Burton JR, Leach AJ. Coronary bypass graft fate: angiographic grading of 1400 consecutive grafts early after operation and of 1132 after one year. Circulation. 1978;57:1070-4.

8. Kieser TM, Rose S, Kowalewski R, Belenkie I. Transit-time flow predicts outcomes in coronary artery bypass graft patients: a series of 1000 consecutive arterial grafts. European Journal of Cardiothoracic Surgery 2010; (38): 155-162.

9. Hattler B, Messenger JC, Shroyer AL, Collins JF, Haugen SJ, Garcia JA, et al. Veterans Affairs Randomized on/off Bypass (ROOBY) Study Group. Off-pump coronary artery bypass surgery is associated with worse arterial and saphenous vein graft patency and less effective revascularization: Results from the Veterans Affairs Randomized On/Off Bypass (ROOBY) trial. Circulation. 2012;125:2877-2835.

10. Puskas JD, Williams WH, O'Donnell R, Patterson RE, Sigman SR, Smith AS, et al. Off-pump and onpump coronary artery bypass grafting are associated with similar graft patency, myocardial ischemia, and freedom from reintervention: Long-term follow-up of a randomized trial. Ann Thorac Surg. 2011;91:1836-42. discussion 1842-1843.

11. Singh SK, Desai ND, Chikazawa G, et al. The Graft Imaging to Improve Patency (GRIIP) clinical trial results. J Thorac Cardiovasc Surg. 2010;139(2):294-301.

12. Jacquelyn Quin J, Lucke B, Hattler, et al. Surgeon Judgment and Utility of Transit Time Flow Probes in Coronary Artery Bypass Grafting Surgery. JAMA Surg. 2014;149(11):1182.

13. Leacche M, Balaguer JM, Byrne JG. Intraoperative grafts assessment. Semin Thorac Cardiovasc Surg. 2009;21:207-12.

14. Nordgaard HB, Vitale N, Astudillo R, et al. Pulsatility index variations using two different transit-time flowmeters in coronary artery bypass surgery. Eur J Cardiothorac Surg. 2010;37:1063-7. 
15. Schmitto JD, Rajab TK, Cohn LH. Prevalence and variability of internal mammary graft use in contemporary multivessel coronary artery bypass graft. Curr Opin Cardiol. 2010;25:609-12.

16. Sabik JF III, Blackstone EH, Gillinov AM, Banbury MK, Smedira NG, Lytle BW. Influence of patient characteristics and arterial grafts on freedom from coronary reoperation. J Thorac Cardiovasc Surg. 2006;131:90-8.

17. Hess CN, Lopes RD, Gibson CM, Hager R, Wojdyla DM, Englum BR, et al. Saphenous vein graft failure after coronary artery bypass surgery: Insights from PREVENT IV. Circulation. 2014;130:1445-51.

18. Kim HJ, Lee TY, Kim JB, et al. The impact of sequential versus single anastomoses on flow characteristics and mid-term patency of saphenous vein grafts in coronary bypass grafting. $\mathrm{J}$ Thorac Cardiovasc Surg. 2011;141:750-4.

\section{Figures}

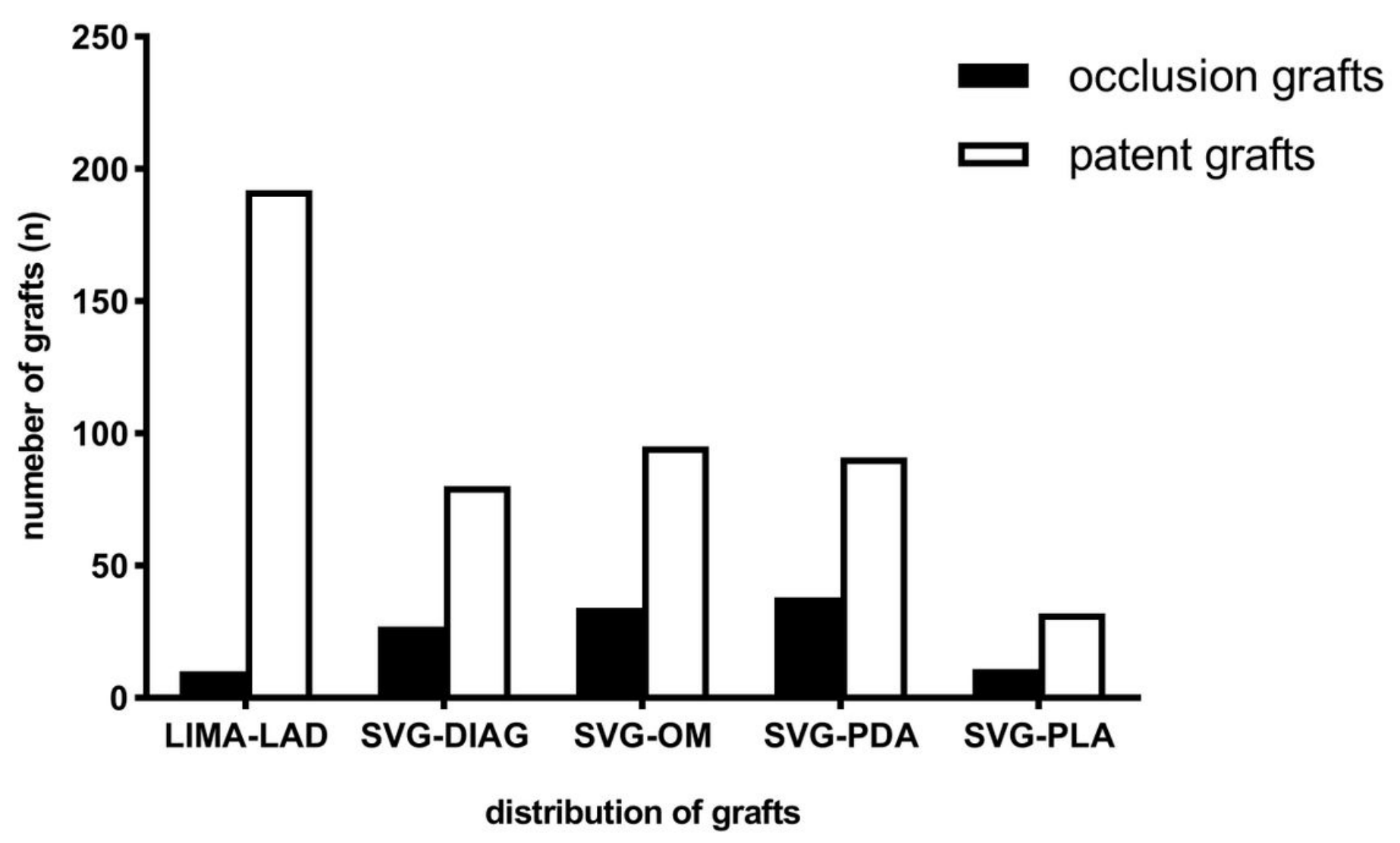

Figure 1

Distribution and angiographic outcomes of bypass grafts. Abbreviations: LIMA, left internal mammary artery; SVG, saphenous vein graft; LAD, left anterior descending artery; DIAG, diagonal artery; OM, obtuse marginal branch of circumflex artery; PDA, posterior descending artery; PLA, left posterior artery. 


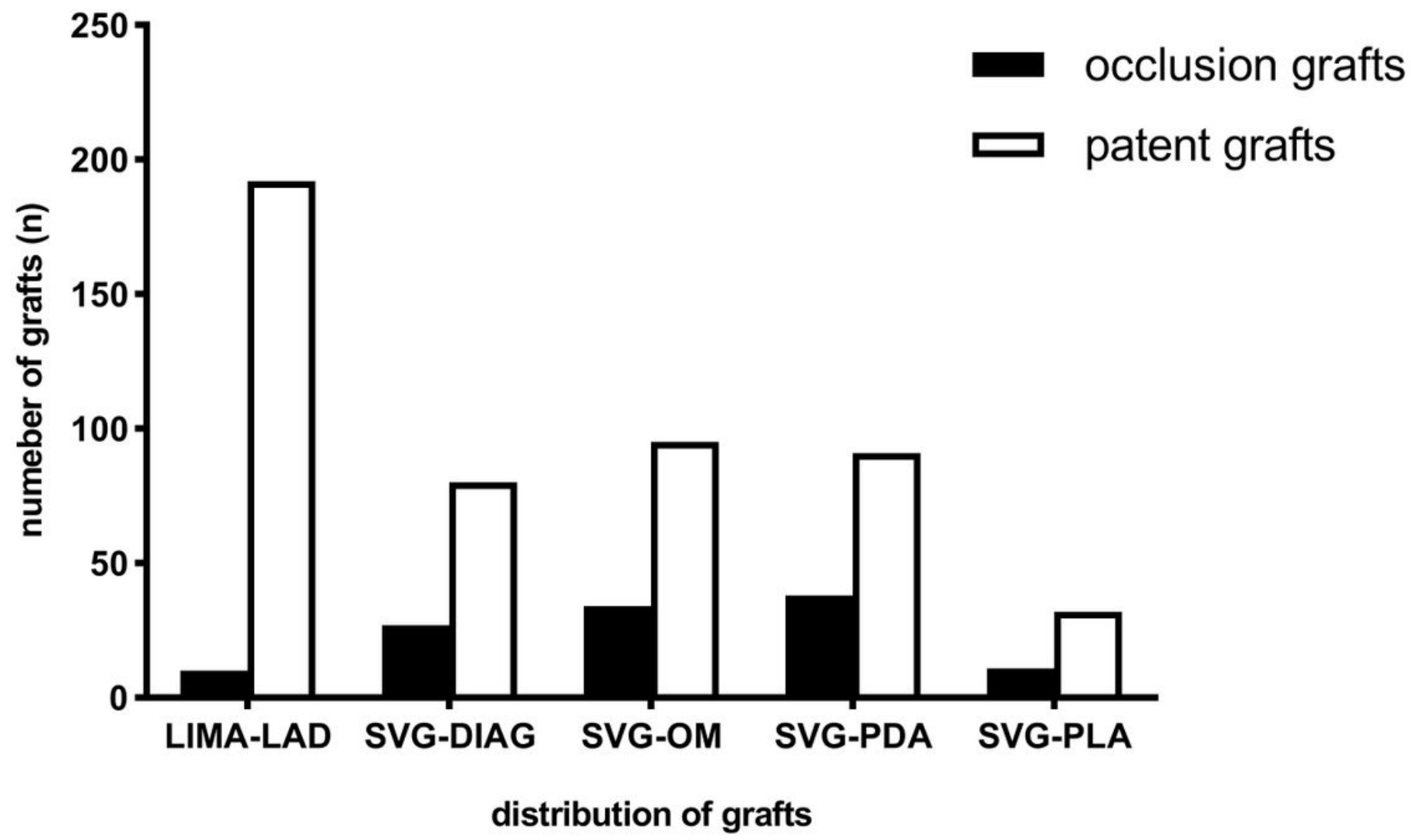

Figure 1

Distribution and angiographic outcomes of bypass grafts. Abbreviations: LIMA, left internal mammary artery; SVG, saphenous vein graft; LAD, left anterior descending artery; DIAG, diagonal artery; OM, obtuse marginal branch of circumflex artery; PDA, posterior descending artery; PLA, left posterior artery. 
SVG-DIAG

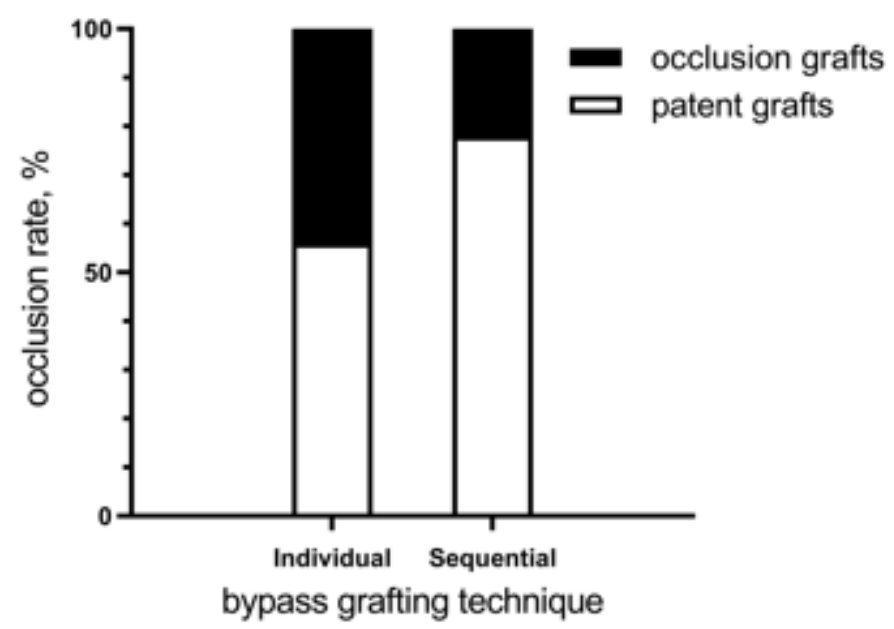

SVG-PDA

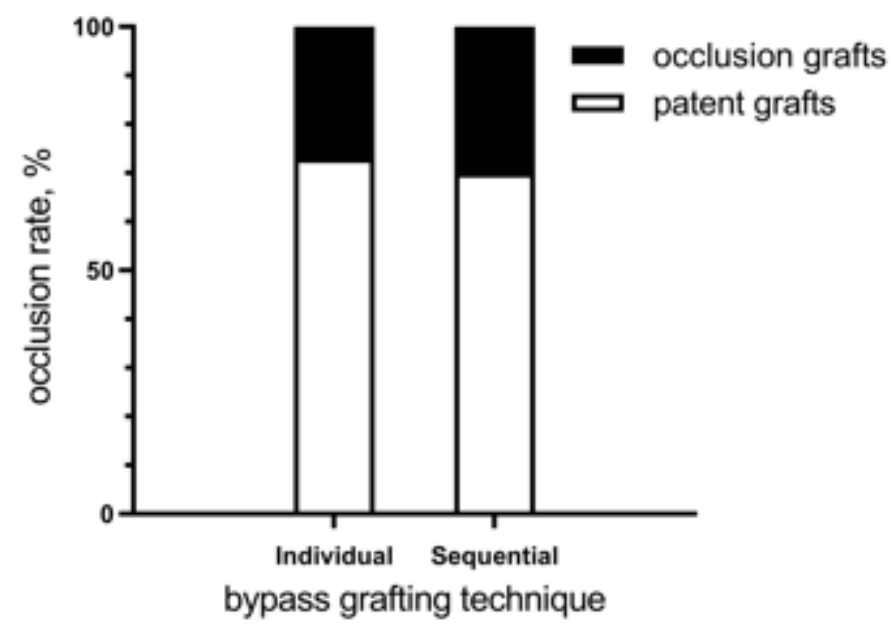

SVG-OM

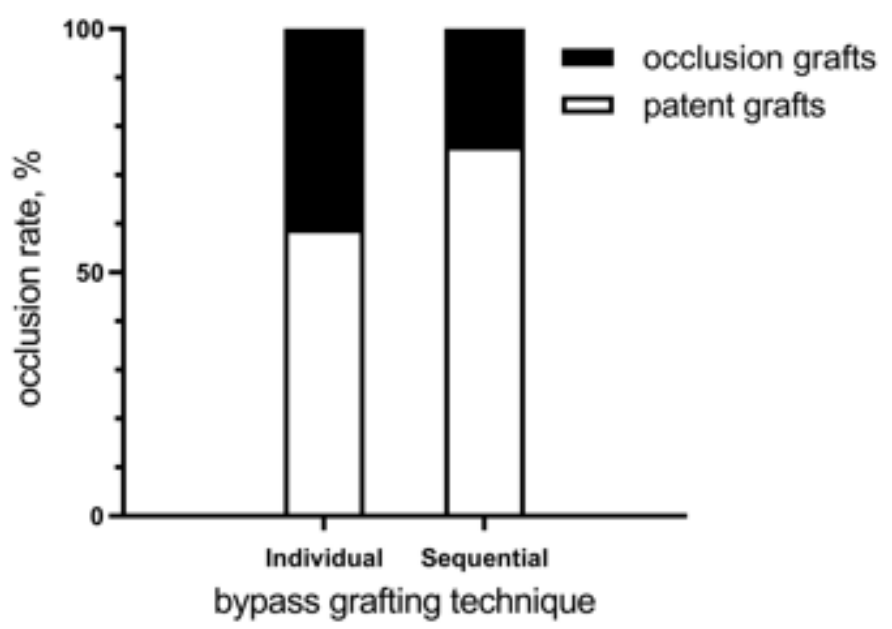

SVG-PLA

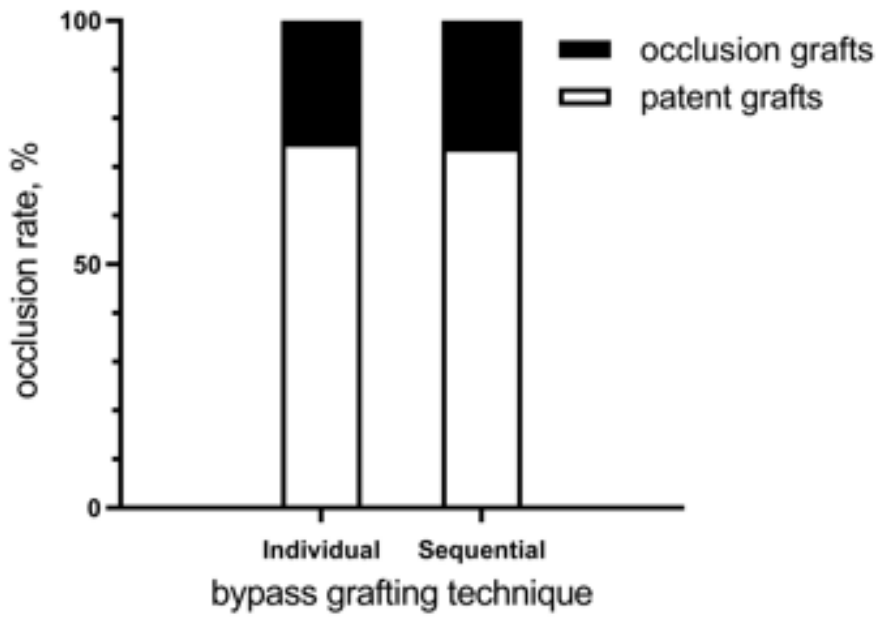

Figure 2

angiographic outcomes of different bypass grafting technique in SVG. Abbreviations: SVG, saphenous vein graft; DIAG, diagonal artery; OM, obtuse marginal branch of circumflex artery; PDA, posterior descending artery; PLA, left posterior artery. 
SVG-DIAG

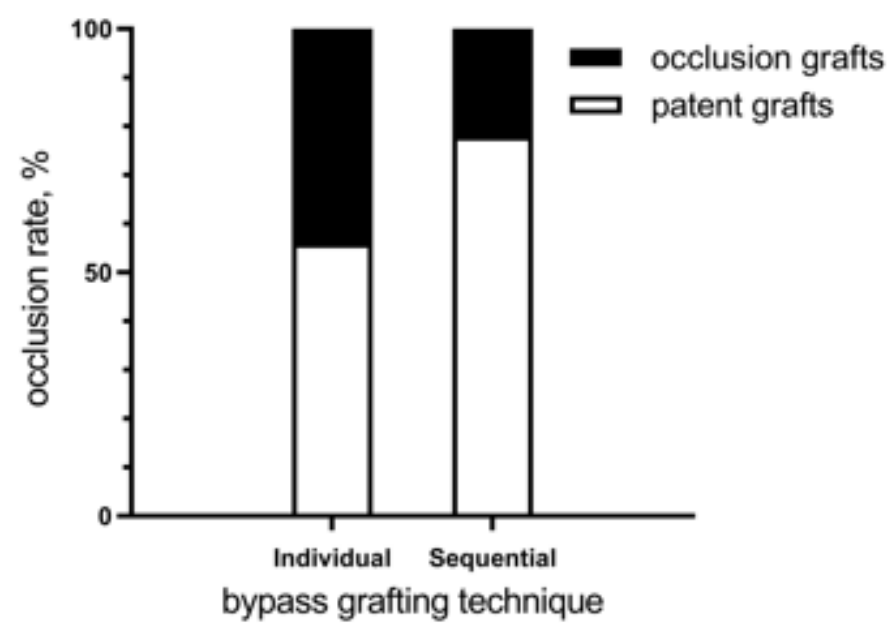

SVG-PDA

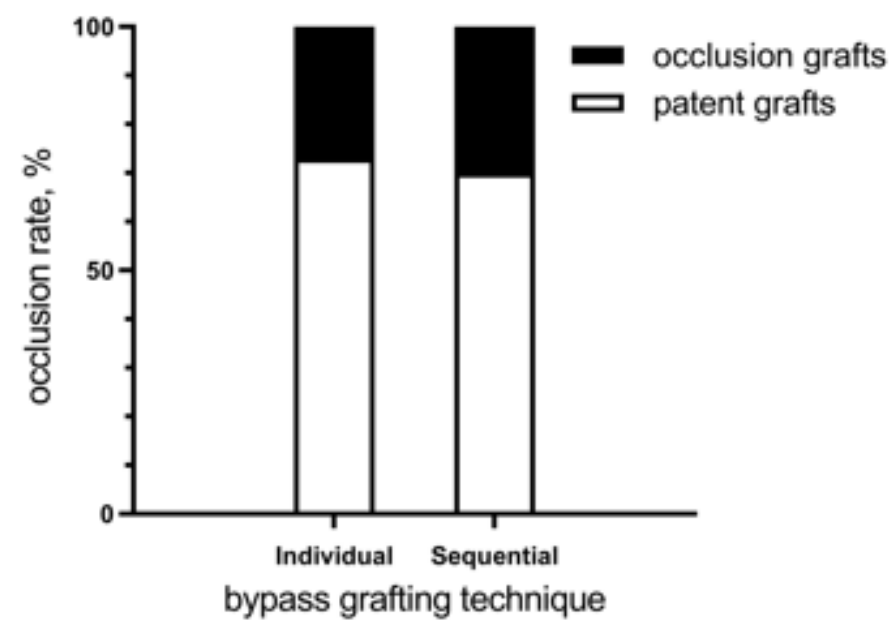

SVG-OM

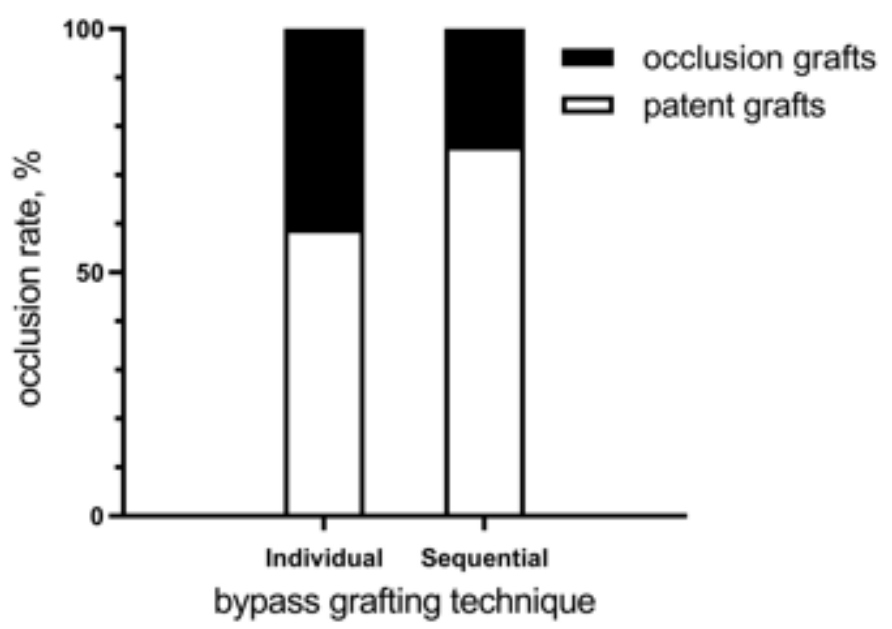

SVG-PLA

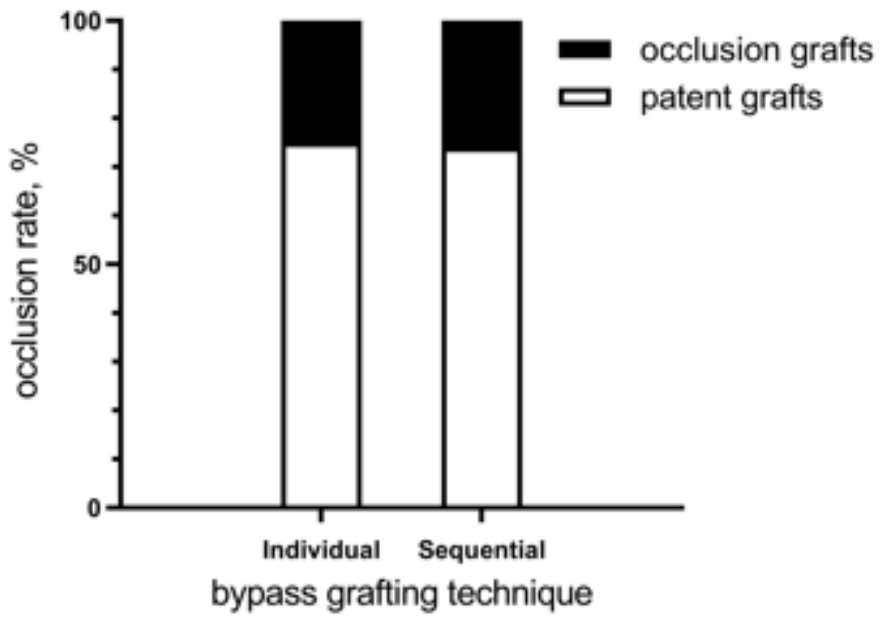

Figure 2

angiographic outcomes of different bypass grafting technique in SVG. Abbreviations: SVG, saphenous vein graft; DIAG, diagonal artery; OM, obtuse marginal branch of circumflex artery; PDA, posterior descending artery; PLA, left posterior artery. 

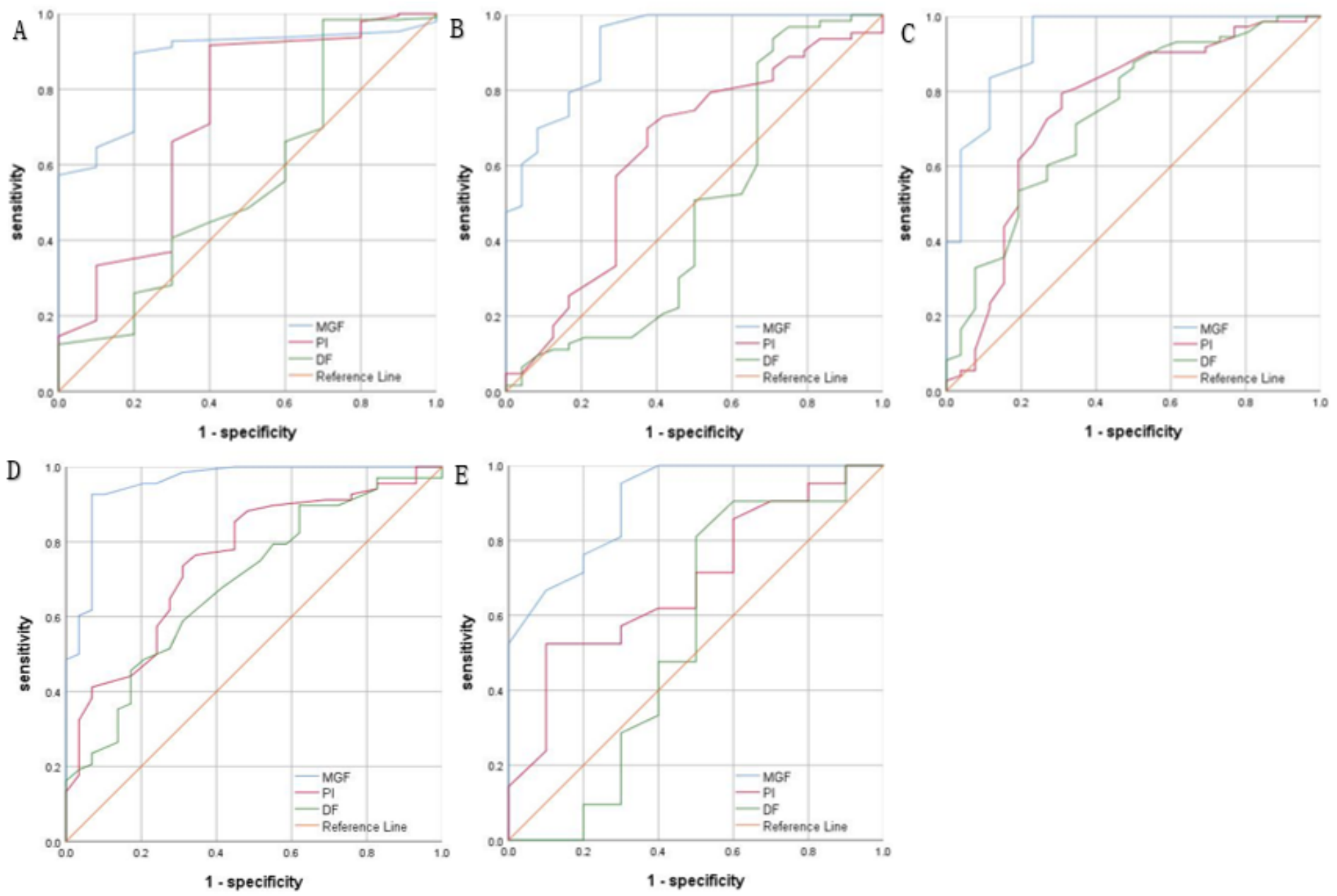

\section{Figure 3}

ROC curve of bypass graft. (A)ROC curve of LIMA; (B) ROC curve of DIAG; (C) ROC curve of OM; (D) ROC curve of PDA; (E) ROC curve of PLA. Abbreviations: ROC, receiver operating characteristic. LIMA, left internal mammary artery; DIAG, diagonal artery; OM, obtuse marginal branch of circumflex artery; PDA, posterior descending artery; PLA, left posterior artery; SVG, saphenous vein graft; MGF, mean graft flow; $\mathrm{PI}$, pulsatile index; $\mathrm{DF}$, diastolic filtration. 

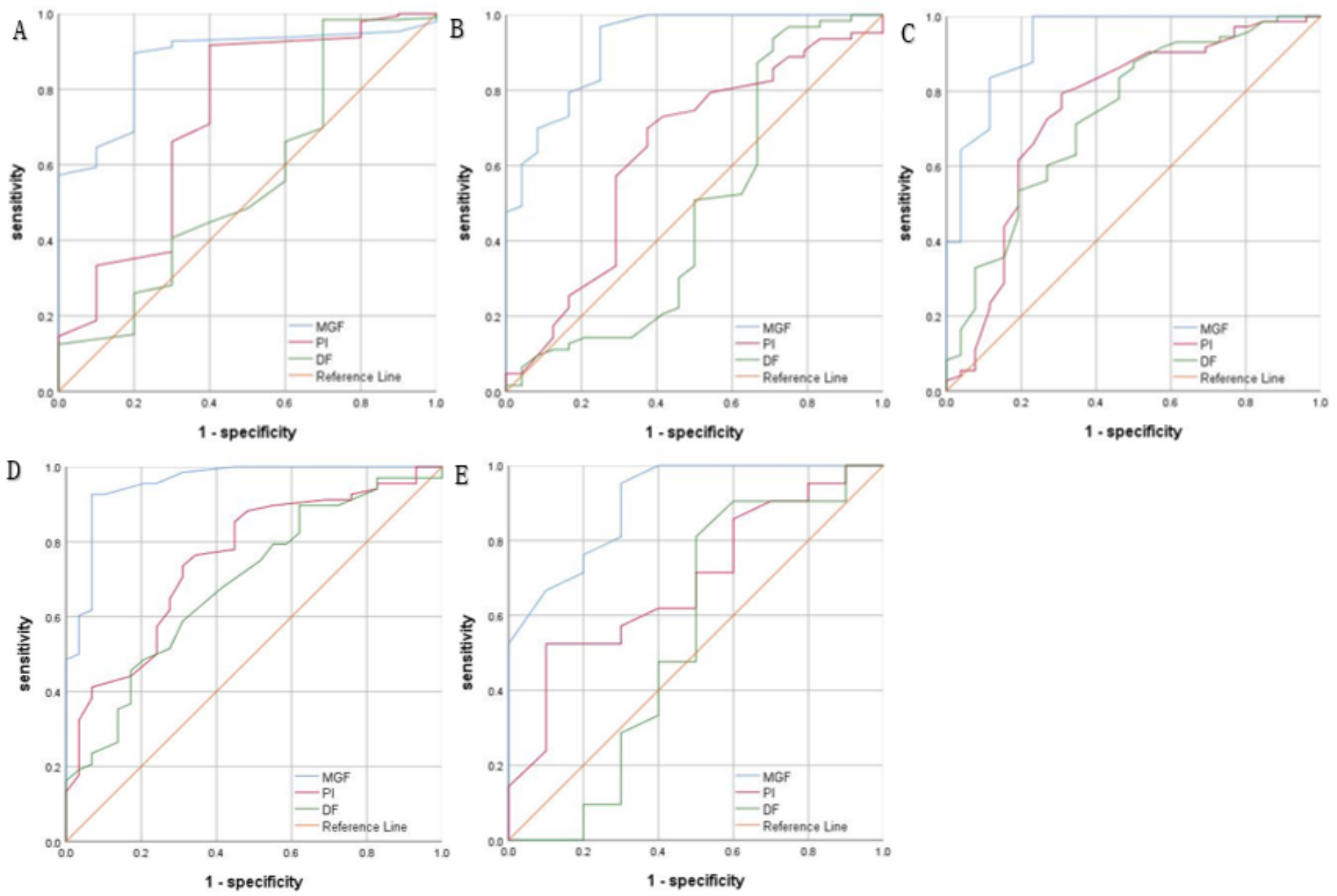

\section{Figure 3}

ROC curve of bypass graft. (A)ROC curve of LIMA; (B) ROC curve of DIAG; (C) ROC curve of OM; (D) ROC curve of PDA; (E) ROC curve of PLA. Abbreviations: ROC, receiver operating characteristic. LIMA, left internal mammary artery; DIAG, diagonal artery; OM, obtuse marginal branch of circumflex artery; PDA, posterior descending artery; PLA, left posterior artery; SVG, saphenous vein graft; MGF, mean graft flow; $\mathrm{PI}$, pulsatile index; $\mathrm{DF}$, diastolic filtration. 